ISSN 2525-4804

\title{
CARACTERIZAÇÃO QUÍMICA E APROVEITAMENTO BIOTECNOLÓGICO DO ABRICÓ AMAZÔNICO (Mammea americana)
}

\author{
Caroline Falcão Rodrigues ${ }^{1}$, Klenicy Kazumy de Lima Yamaguchi ${ }^{2}$
}

\section{RESUMO}

A região Amazônica é rica em frutas exóticas e entre elas tem-se o abricó (Mammea americana) pertencente à família Clusiaceae. Com este trabalho, objetivou-se realizar a caracterização química e elaborar um produto biotecnológico a partir do abricó visando o aproveitamento total do fruto. Os métodos empregados neste estudo foram a prospecção fitoquímica e o desenvolvimento de geleia e barra de cereais utilizando casca, polpa e semente do fruto. A análise fitoquímica revelou a presença de substâncias fenólicas, antocianidinas, chalconas, leucoantocianidinas e catequinas nas cascas e sementes. O produto elaborado obteve atributos satisfatórios e com grande potencial, tendo utilizado a fruta de forma integral. Este estudo abre a perspectiva de agregar valor a essa fruta, rica em substâncias bioativas, mas que é desconhecida pela maior parte da população brasileira.

Palavras Chaves: Amazônia. Frutos amazônicos. Prospecção fitoquímica.

\section{CHEMICAL CHARACTERIZATION AND BIOTECHNOLOGICAL APPLICATIONS OF THE AMAZON ABRICÓ (Mammea americana)}

\begin{abstract}
:
The Amazon region is rich in exotic fruits and one of them is the abrico (Mammea americana), it belongs to Clusiaceae family. The objective of this work was to carry out the chemical characterization and develop a biotechnological product from abrico aiming at the full use of this fruit. The methods used were the phytochemical prospecting and the development of jam and cereal bar using peel, pulp and seed of the fruit. The Phytochemical analysis showed the presence of phenolic, anthocyanidins, chalcones, leucoanthocyanidins and catechins substances in the peel and seeds. The developed product obtained satisfactory attributes with great potential, having used all the parts of the fruit. This study opens the perspective of adding value to this fruit which is rich in bioactive substances and is still little known by the Brazilian population.
\end{abstract}

Keywords: Amazon. Amazonian Fruits. Chemical characterization.

\footnotetext{
${ }^{1}$ Graduanda em Biotecnologia, Instituto de Saúde e Biotecnologia, Universidade Federal do Amazonas (UFAM), Coari, AM. carolliner19@gmail.com

${ }^{2}$ Bacharel em Química e em Farmácia, Doutora e mestre em Química. Professora Adjunta no Instituto de Saúde e Biotecnologia, Universidade Federal do Amazonas (UFAM), Coari, AM. klenicy@gmail.com
} 
As pesquisas relacionadas ao aproveitamento de frutas estão cada vez mais em expansão, conduzindo estudos que possam detectar a composição química e sugerir alternativas de utilização, como a produção de suco, doce, concentrados para refrigerante, xaropes, sorvetes, geleias e outros que possam agregar valor ao produto final. Estes trabalhos atuam minimizando os desperdícios e possibilitando a geração de novos produtos biotecnológicos (ORDONES-SANTOS et al., 2014; NASCIMENTO, RODRIGUES e SILVA, 2020).

Nesse cenário, a região Amazônica é rica em possibilidades de aproveitamento das frutas, com espécies exóticas muito utilizadas pela população, no entanto, pouco exploradas industrialmente (SOUZA et al., 2011). Entre eles, tem-se o abricó (Mammea americana) como um fruto exótico e pouco conhecido dos demais estados brasileiros. Essa espécie é cultivada na América do Sul, principalmente Venezuela, Guiana, Guiana Francesa, Suriname, Equador e região norte do Brasil. A espécie tem como nome popular abricó, abricó-dopará, castanha-de-macaco, abricó-de-macaco e cuiade-macaco. "Mamey", "mamey dominicano" (espanhol), "mamme", "mammee-apple" (inglês), "abricot de Saint Domingue" (francês) (FERREIRA e RIBEIRO, 2006).

A árvore é empregada na arborização urbana e na medicina popular no tratamento de afecções parasitárias, picada de insetos e dermatoses diversas. As partes utilizadas são o leite da casca da planta, o pó obtido das sementes e chá das folhas (FERREIRA e RIBEIRO, 2006). Os frutos são drupas globosas e volumosas, com até $25 \mathrm{~cm}$ de diâmetro, com peso de até um quilo (podendo chegar até $2 \mathrm{~kg}$ ). Suas cascas são rugosas, coriáceo-flexível de cor pardoalaranjada, mesocarpo (parte comestível) constituído de uma polpa compacta, firme, fibrosa, cor de abóbora, sementes ovaladas, plano-convexas, com 6$8 \mathrm{~cm}$ de comprimento, imersas na polpa e envolvidas pelo endocarpo rugoso (CAVALCANTE, 1991).

O maior consumo desta fruta é in natura, sendo descrito em baixa escala o uso em licores, compotas, geleias e sucos. É uma espécie conhecida como medicinal, sendo utilizada pela população no tratamento de parasitoses, hipertensão arterial e equilíbrio de ácido úrico. Pesquisas científicas descrevem os metabólitos da fruta com propriedades antioxidantes, antimicrobianos e inseticidas (MOSQUERA et al., 2020; LITTLE et al., 2017; YANG et al., 2006). No estudo de Mosquera et al. (2020), detectou-se a capacidade antimicrobiana de fungos endofíticos, obtidos desse fruto, para cepas resistentes de Staphylococcus aureus e Escherichia coli.

A colheita ainda tem caráter extrativista, onde depois da coleta os frutos são repassados para intermediários a um baixo custo e revendidos em mercados maiores a um valor mais elevado. No cenário atual, a demanda é pequena e destinada apenas aos consumidores locais, e por ser uma fruta silvestre poucos são os dados disponíveis sobre sua produção e comercialização (BRAGA et al., 2010).

Poucos são os dados na literatura sobre a caracterização química dos frutos de abricó. Na polpa já foram detectados potássio, vitamina A e C, cumarinas, fenólicos e carotenoides (NASCIMENTO et al., 2008; BRAGA et al., 2010; MOURÃO e BELTRATI, 2000). Mesmo com a detecção das potencialidades biológicas desta espécie, os estudos sobre a aplicação biotecnológica e a caracterização das outras partes, sementes e cascas, são escassos. Diante disso, o objetivo deste trabalho é realizar a caracterização química e elaborar um produto biotecnológico a partir do abricó visando o aproveitamento total do fruto.

O trabalho foi realizado no laboratório de química orgânica e no laboratório de técnica dietética do Instituto de Saúde e Biotecnologia da Universidade Federal do Amazonas, localizado no município de Coari/AM. O fruto abricó, foi coletado na vila São José do Amatari, comunidade de Itacoatiara/AM, Brasil.

Foi realizada a assepsia do abricó com água destilada e solução sanitizante e utilizado os frutos de diferentes tamanhos, contudo, com o mesmo grau aparente de maturação. Em seguida, os frutos foram 
cortados e separadas suas partes: polpa, casca e semente, que foram devidamente pesadas. As cascas e as sementes foram secas ema estufa (marca Deleo), a temperatura de $60{ }^{\circ} \mathrm{C}$ por $72 \mathrm{~h}$. Após isso, o material vegetal (cascas e sementes) foi triturado em um moinho de quatro facas e em liquidificador industrial, onde posteriormente foi realizado as obtenções dos extratos orgânicos.

Os extratos do material vegetal obtido foram realizados em triplicata por meio de três diferentes técnicas de maceração: maceração a frio por $24 \mathrm{~h}$, maceração a quente por $30 \mathrm{~min}$ e maceração sob agitação por $30 \mathrm{~min}$. Utilizou-se um grama (1g) de cada parte do material e $10 \mathrm{~mL}$ de etanol como solvente extrator, permitindo otimizar o sistema de extração.

A caracterização química foi analisada por meio de Prospecção Fitoquímica, onde seguiu-se a metodologia descrita por Matos (1997). Foram realizados oito testes para detectar a ausência ou a presença de metabolitos secundários presentes no extrato das cascas e sementes. Foram utilizados três gramas (3 g) do pó da casca e semente, separadamente, solubilizado em $6 \mathrm{~mL}$ de água e 24 $\mathrm{mL}$ de etanol (solução hidroalcólica).

As detecções foram realizadas usando reagentes específicos para cada teste em particular. Dentre as várias substâncias existentes, foram feitos testes para identificação de triterpenóides, esteroides, saponinas, cumarinas, compostos fenólicos, antraquinonas, antocianidinas, chalconas, leucoantocianidinas, catequinas e flavononas.

O produto biotecnológico foi elaborado no laboratório de nutrição técnica dietética da Universidade Federal do Amazonas, seguindo todos os padrões de manipulação e segurança. Foi elaborado uma geleia da polpa do fruto em que se utilizou $1,56 \mathrm{~kg}$ da polpa, $300 \mathrm{~g}$ de açúcar e $300 \mathrm{~mL}$ de água e deixado no fogo por $45 \mathrm{~min}$ em uma temperatura de $180^{\circ} \mathrm{C}$.

$\mathrm{Na}$ elaboração da barra de cereal, empregouse a geleia da casca e polpa do fruto. Foram utilizados $170 \mathrm{~g}$ de polpa e $90 \mathrm{~g}$ da casca do fruto seco, totalizando $260 \mathrm{~g}$ de material. As cascas foram colocadas em água fervente por $1 \mathrm{~min}$, em seguida acrescentou-se a polpa, e a mistura permaneceu em aquecimento por mais $2 \mathrm{~min}$. Após esse processo, as cascas e a polpa foram colocadas em outro recipiente com água e gelo, num processo denominado de branqueamento, com duração por $3 \mathrm{~min}$, objetivando inativar as enzimas causadoras do gosto amargo existente nas cascas. Os mesmos foram colocados no liquidificador com $150 \mathrm{~mL}$ de água para a trituração. Posteriormente, foram despejados em uma panela e foram adicionados $161 \mathrm{~g}$ de açúcar e $25 \mathrm{~mL}$ de bebida aguardente alcoólica junto a mistura da polpa e casca. Levou-se para o fogo em temperatura de $180{ }^{\circ} \mathrm{C}$ por 15 min. Em seguida, passou-se em uma peneira para retirar os resíduos.

Para a elaboração da barra de cereal, foram utilizadas sete bananas pacovãs (1411 g), sendo 651 $\mathrm{g}$ de cascas e $796 \mathrm{~g}$ de polpa. As cascas e as polpas desse fruto passaram pelo processador adquirindo cortes em pequenos pedaços, despejados em uma bandeja e levados para estufa de ar circulante a temperatura de $85{ }^{\circ} \mathrm{C}$ por $10 \mathrm{~h}$. Da amêndoa da semente do abricó triturado, foi feito chocolate adicionando-se uma caixa de leite condensado e levado ao fogo até ao ponto do chocolate. Com isso, foram elaboradas 29 barras de cereais que ficaram sem o recheio de chocolate e 21 barras com recheio de chocolate, tento como total 50 barras de cereais no tamanho de $10 \mathrm{~cm}$ de comprimento por $3 \mathrm{~cm} \mathrm{de}$ largura.

Os resultados obtidos das extrações do material vegetal por macerações foram analisados por meio de rendimento, média e desvio padrão (Tabela 1). De maneira geral não foi possível observar diferenças entre os rendimentos médios nas diferentes técnicas de maceração testados. Dessa forma, considera-se que as técnicas de maceração, seja à quente, sob agitação ou a frio, apresentam-se como procedimentos capazes de extrair metabólitos secundários de forma rápida e com poucos recursos.

Os valores dos rendimentos médios dos extratos vegetais são importantes, pois demonstram o potencial do produto para utilização em larga escala de produção. 
Tabela 1. Rendimentos, média \pm desvio padrão das extrações pelo processo de maceração a quente, sob agitação e a frio da casca e semente do abricó.

\begin{tabular}{|c|c|c|c|c|c|}
\hline \multicolumn{2}{|c|}{ Maceração a quente } & \multicolumn{2}{|c|}{ Maceração sob agitação } & \multicolumn{2}{|c|}{ Maceração a frio } \\
\hline Amostras & Rendimentos (\%) & Amostras & Rendimentos (\%) & Amostras & Rendimentos (\%) \\
\hline Casca1 & $10,60 \%$ & Casca1 & $10,30 \%$ & Casca1 & $10,10 \%$ \\
\hline Casca2 & $10,30 \%$ & Casca2 & $9,50 \%$ & Casca2 & $9,10 \%$ \\
\hline Casca3 & $10,70 \%$ & Casca3 & $10,70 \%$ & Casca3 & $9,50 \%$ \\
\hline $\begin{array}{c}\text { Média } \pm \\
\text { Desvio } \\
\text { padrão }\end{array}$ & $10,53 \pm 0,169$ & $\begin{array}{c}\text { Média } \pm \\
\text { Desvio } \\
\text { padrão }\end{array}$ & $10,16 \pm 0,498$ & $\begin{array}{c}\text { Média } \pm \\
\text { Desvio } \\
\text { padrão }\end{array}$ & $9,566 \pm 0,410$ \\
\hline Semente1 & $6,30 \%$ & Semente1 & $4,30 \%$ & Semente1 & $3,20 \%$ \\
\hline Semente 2 & $4,70 \%$ & Semente2 & $4,00 \%$ & Semente2 & $2,20 \%$ \\
\hline Semente 3 & $4,40 \%$ & Semente 3 & $4,10 \%$ & Semente3 & $2,70 \%$ \\
\hline $\begin{array}{c}\text { Média } \pm \\
\text { Desvio } \\
\text { padrão }\end{array}$ & $5,13 \pm 0,833$ & $\begin{array}{c}\text { Média } \pm \\
\text { Desvio } \\
\text { padrão }\end{array}$ & $4,13 \pm 0,124$ & $\begin{array}{c}\text { Média } \pm \\
\text { Desvio } \\
\text { padrão }\end{array}$ & $2,7 \pm 0,408$ \\
\hline
\end{tabular}

Os materiais vegetais (casca e semente) foram submetidos às análises para a determinação das principais classes químicas de metabólitos especiais. Os constituintes químicos encontrados na prospecção fitoquímica dos extratos da casca e semente do abricó estão descritos na tabela 2. Os resultados são demonstrados pela presença e ausência dos metabólitos, sendo que o sinal positivo (+) indica a presença e o sinal negativo (-) ausência dos mesmos.

A presença de compostos fenólicos foi confirmada pela coloração azul escura obtida no ensaio realizado, tanto para as sementes, quanto para as cascas. Os compostos fenólicos são caracterizados por conter em sua estrutura química anel aromático com um ou mais substituintes hidroxílicos, incluindo seus grupos funcionais. Estes compostos são essenciais para o desenvolvimento dos vegetais e são classificados como antioxidantes naturais, sendo capazes de interagir com espécies radiculares (RAMALHO e JORGE 2006).

Antocianinas e chalconas foram evidenciadas pela presença de cor intensa vermelha nos tubos de ensaio onde foram realizados os testes. As antocianinas são grupos de pigmentos naturais com estruturas fenólicas variadas, representam um significante papel na prevenção ou retardam o aparecimento de várias doenças por suas propriedades antioxidantes (ARAÚJO, 2008).

Tabela 2. Classes de metabólitos secundários presentes no extrato obtido a partir da casca e semente do fruto abricó. Fonte: As autoras (2020).

\begin{tabular}{ccc} 
Classes de metabólitos & \multicolumn{2}{c}{ Material Vegetal } \\
\cline { 2 - 3 } secundários & Casca & Semente \\
\hline Triterpenóides e esteroides & - & - \\
Saponinas & - & - \\
Cumarinas & + & - \\
Compostos fenólicos & + & + \\
Antraquinonas & - & - \\
Antocianidinas e chalconas & + & + \\
Leucoantocianidinas e & + & + \\
catequinas & + & - \\
Flavononas & &
\end{tabular}

As chalconas atuam nas plantas e frutos com ação antioxidantes, antimicrobianos, antifúngicos, fotoreceptores, atraentes visuais e repelentes de 
predadores. São compostos precursores da via de biossíntese de flavonóides, que apresentam pigmentação amarela que passa a vermelha em meio alcalino (ZUANAZZI, 2002).

O parâmetro indicador de leucoantocianidinas e catequinas foi o aparecimento de cor vermelha para leucoantocianidinas e a cor amarelo para catequinas. As leucoantocianidinas são importantes por terem propriedades de aumento de tonicidade e resistência das paredes capilares, aplicado para tratamento de várias doenças que envolvem veias e artérias (INFINITY PHARMA, 2012).

As catequinas possuem como características principais o gosto amargo, incolor e hidrossolúveis.
Tem como benefícios a saúde humana a redução do surgimento de certos tipos de câncer, redução do colesterol e estimulação do sistema imunológico (PEREIRA; CARDOSO 2012).

A barra de cereal (Figura 1), produto biotecnológico obtido, a partir de uma base de banana, adicionando sementes e cascas de abricó, apresentou coloração creme, gosto adocicado e maciez. O diferencial do estudo reflete-se no uso de um produto alimentício utilizando matérias-primas comumente descartadas, mas que apresentam elevado potencial biológico.

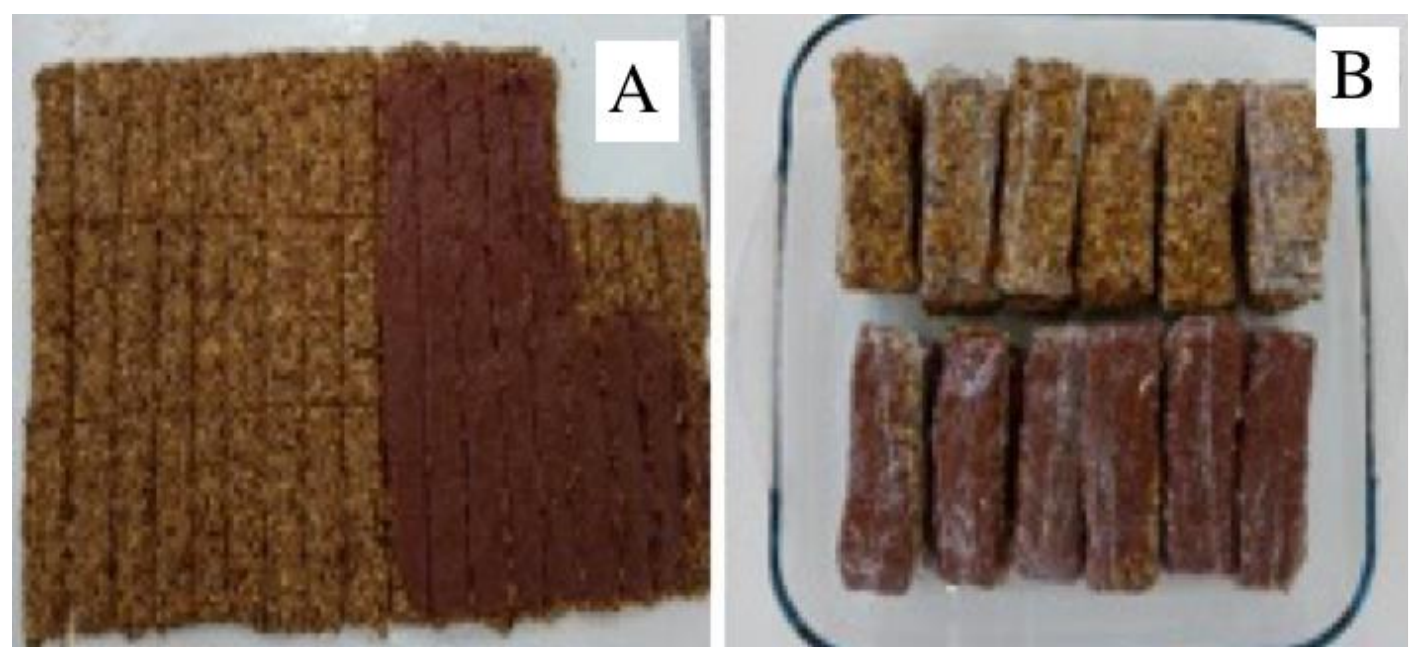

Figura 1: Barra de cereal produzida a partir da geleia de abricó. (A) produto sendo elaborado; (B) Barras de cereais. Fonte: Autor (2020).

O fruto do abricó é rico em fibras, betacaroteno, tem ação antioxidante, fortalece $\mathrm{o}$ sistema imune dentre outros requisitos benéficos (CAVALCANTE, 1991). Desta forma, o consumo de produtos obtidos deste fruto possui qualidades nutricionais importantes para alimentação humana. Através dos resultados observados, o aproveitamento total do fruto de abricó (casca, polpa e sementes) é possível para elaboração de produtos industriais deste fruto. $\mathrm{O}$ uso de subprodutos agroindustriais, como as cascas e as sementes, pode servir de grandes incrementos em produtos alimentícios, garantindo um bom enriquecimento nutricional com baixo custo, além de importante tarefa do reaproveitamento dos mesmos (BECKER; KRÜGER, 2010), agregando valor ao produto.

Levando-se em consideração os resultados observados neste estudo, observou-se que todas as técnicas de maceração analisadas apresentaram um bom desempenho na extração do fruto de abricó. A caracterização química demonstrou a presença de classes metabólicas bioativas importantes para o equilíbrio nutricional do organismo, através do consumo do fruto.

O aproveitamento total do fruto do abricó observado abre a perspectiva de agregar valor ao que 
é considerado descarte na agroindústria. A satisfatória composição química do fruto e a elaboração de um produto com potencial para consumo poderá contribuir para a utilização sustentável de matérias-primas amazônicas. Sabe-se que ainda há muito a ser descoberto sobre o abricó e este estudo possibilitou maiores informações sobre a aplicabilidade deste fruto. Com isso, estudos futuros são incentivados buscando analisar os produtos advindos desta matéria-prima para o mercado industrial, através de outros testes como a aceitação da população através de análises sensoriais, tendo em vista o potencial apresentado com grande benefício à saúde, além da valorização de um fruto exótico e nativo da região amazônica.

\section{REFERÊNCIAS BIBLIOGRÁFICAS}

Araújo, J. M. (2008) Química de Alimentos: Teoria e Prática. 4. Ed. Viçosa: Editora UFV, 477p.

Becker, T. S.; Krüger, R. L. (2010) Elaboração de barras de cereais com ingredientes alternativos e regionais do Oeste do Paraná. Arquivos de Ciência e Saúde UNIPAR, 14(3): 217-224.

Braga, A. C. C.; Silva, A. E.; Pelais, A. C. A.; Bichara, C. M. G. Pompeu, D. R. (2010) Atividade antioxidante e quantificação de compostos bioativos dos frutos de abricó (Mammea americana). Alimentos e Nutrição, 21(1):31-36.

Cavalcante, P. B. (1991) Frutas comestíveis da Amazônia. 5. ed. Belém: CEJUP, 279 pg.

Ferreira M.G.R.; Ribeiro, G.D. (2006) Coleção de fruteiras tropicais da Embrapa Rondônia. Porto Velho, RO: Embrapa Rondônia, 14 p. (Comunicado Técnico, 306). Disponível em: http://www.cpafro.embrapa.br/media/arquivos/publi cacoes/cot306fruteiras. pdf

Infinity Pharma. (2020) Leucoantocianidinas. Potente protetor contra danos vasculares. Disponivel em: <http:// infinitypharma.com.br/uploads/insumos/pdf/l/Leuco antocianidina_2.pdf $>$. Acesso em: 07 de Ago. de 2020
Little, E. L.; Woodbury, R.; Wadsworth, F. H. (1974) Trees of Puerto Rico and the Virgin Islands. USDA. Agriculture Handbook 449. Disponível em:: http://edicionesdigitales.info/biblioteca/arbolesprvi2 engl.pdf Acesso em: 07 de Ago. de 2020

Matos, F. J. A. (1997) Introdução a fitoquímica experimental. 2. ed. Fortaleza: Edições UFC. 141 p.

Mosquera, W. G.; Criado, L. Y.; Guerra, B. E. (2020) Actividad antimicrobiana de hongos endófitos de las plantas medicinales Mammea americana (Calophyllaceae) y Moringa oleifera (Moringaceae). Biomédica, 40(1): 55-71.

Mourão, K. S. M.; C. M. B. (2000). Morphology and anatomy of developing fruits and seeds of Mammea americana L. (Clusiaceae). Revista Brasileira de Biologia,60(1):701-711.

Nascimento, C. S.; Rodrigues, A. M. C.; Silva, L. H. M. (2020) Development of a dehydrated product with edible film characteristics from mammee apple (Mammea americana L.) using Refractance Window drying. Food Science and Technology, 40(1):245249.

Nascimento, W. M. O.; Carvalho, J. E. U.; Müller, C. H. (2008) Propagação do Abricoteiro. Comunicado técnico. Belém, PA: Embrapa Amazônia Oriental, 19p.

Oliveira, L. F.; Nascimento, M.R.F.; Borges, S.V.; Ribeiro, P.C.N. \& Ruback, V.R. (2002). Aproveitamento alternativo da casca do maracujáamarelo (Passiflora edulis f. flavicarpa) para produção de doce em calda. Food Science and Technology, 22(3), 259-262. https://doi.org/10.1590/S0101-20612002000300011

Ordonez-Santos, L. E.; Martinez-Alvarez, G. M.; Vazquez-Riascos, A. M. (2014) Effect of processing on the physicochemical and sensory properties of mammee apple (Mammea americana L.) fruit. Agrociencia, 48(4):377-385.

Pereira, R. J.; Cardoso, M. G. (2012) Metabólitos ssecundários vegetais e benefícios antioxidantes. Journal of Biotechnology and Biodiversity,3(4):146-152. 
Ramalho, V. C.; Jorge, N. (2006) Antioxidantes utilizados em óleos, gorduras e alimentos gordurosos. Revista Química Nova,29(4):755-760.

Sousa, Mariana Séfora Bezerra, Vieira, Luanne Morais, \& Lima, Alessandro de. (2011). Fenólicos totais e capacidade antioxidante in vitro de resíduos de polpas de frutas tropicais. Brazilian Journal of Food Technology, 14(3), 202-210. https://doi.org/10.4260/BJFT2011140300024

Yang, H.; Jiang, B.; Reynertson, K. A.; Basile, M. J.; Kennelly, E. J. (2000). Comparative analyses of bioactive Mammea Coumarins from seven parts of Mammea americana by HPLC-PDA with LC-MS. Journal Agriculture and Food Chemistry, 54:41144120. https:/doi.org/10.1021/jf0532462

ZUANAZZI, J.A.S. (2002). Flavonóides. In: SIMÕES, C.M.O. et al.. Farmacognosia: da planta ao medicamento, $4^{\mathrm{a}}$ ed., Porto Alegre/Florianópolis, Ed. Universidade UFRGS/Ed. Da

UFSC, p. 499-526. 